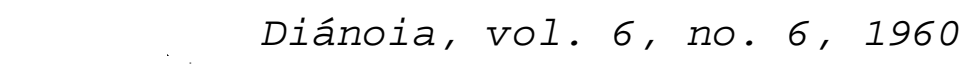

\title{
NATURALEZA Y CULTURA EN ROUSSEAU
}

\section{Naturaleza y cultuta}

"En todas las crisis históricas que se producen por la superabundancia... -observa Ortega y Gasset- el hombre intenta salvarse podando la excesiva fronda cultural, desnudándose y añorando la sencillez primigenia. Al sentirse asfixiado en una cultura superlativa recurre de ella a la naturaleza. Rousseau huye del Versalles de las marquesas al bosque de Fontainebleau para imitar alli a los salvajes. Es curioso: el hombre de las extremas civilizaciones, desesperado, llama al salvaje que sospecha llevar dentro. $Y$ nuestro salvaje interior acude siempre a la cita. Por lo visto, imperecedero, está ahí oculto, siempre pronto a nuestra llamada." 1 Análogamente comenta Gomperz que "cuando nos sentimos oprimidos por las cadenas de rígidos convencionalismos, por las exigencias múltiples de una sociedad complicada, ¿dónde volver la mirada sino a los orígenes del presente, a las civilizaciones primitivas, cuyo espectáculo poéticamente embellecido se nos presenta de esta manera como el modelo del porvenir?... En tales casos suena enérgicamente un grito -al comienzo del siglo Iv a. c. lo lanza Antístenes, a mediados del siglo J. J. Rousseau-: jvolvamos a la naturalezal" 2

Ahora bien, no se malinterprete el sentido peculiar que este grito tiene para Rousseau, sentido que es muy diferente del que posee en los filósofos cínicos de la Antigüedad griega. La naturaleza es sentida por Rousseau, no como animalidad, sino como un ideal de perfección ética. A pesar de las expresiones que usa a veces en elogio de los salvajes, dejándose llevar por la inercia de una moda intelectual de su época o por una poetización circunstancial de la existencia primitiva, la voz de la naturaleza significa para Rousseau la voz de la conciencia humana y una norma moral. Si mira con deliquio al. salvaje es porque a veces llega a creer que en el salvaje podrá percibirse con mayor claridad y autenticidad esa voz deontológica. Mientras que lo que a los cínicos les atrae en los salvajes es su salvajismo, su carácter selvático, en cambio, lo que Rousseau ama en ellos es la espontaneidad de su vida interior que puede hacer que escuchen mejor esa voz ética. Rousseau bajo el influjo de aquellos factores cree que el salvaje conserva más genuinamente el sentido de su propia existencia y de su yo interior. Pero Rousseau no quiere poner su ideal humano en la selva, sin vínculos de familia ni de nación, antes bien,

1 Cf. José Ortega y Gasset, Obras completas, vol. V; págs. 503 y sig., Madrid, 1946.

2 Cf. Th. Gomperz, Griechische Denker, $3^{\mathrm{a}}$ ed., 1911. 
quiere que Emilio sea un salvaje en la vida social, esto es, un hombre auténtico en una civilización genuinamente humana. ${ }^{3}$

A este respecto es muy ilustrativa la correspondencia con Voltaire en torno al Discurso sobre la desigualdad. Mofándose de algunas de las ideàs expuestas por Rousseau en esta obra, escribia Voltaire: "Nadie ha puesto jamás tanto ingenio en querer convertirnos en animales. Se siente el deseo de caminar a cuatro patas cuando se lee vuestro libro. Sin embargo, como hace más de sesenta años que he perdido el hábito de hacerlo, siento desgraciadamente que me sería imposible volver a él, y dejo esta marcha natural a los que son más dignos de ello que vos y yo." A esto Rousseau replicó: "No tratéis de caer nuevamente a cuatro patas; nadie en el mundo lo conseguiría menos que vos. Sabéis muy bien enderezarnos sobre nuestros dos pies para que dejéis de teneros sobre los vuestros:" Voltaire habia interpretado torcidamente a Rousseau, como si éste pretendiese poner a la humanidad a cuatro patas, hacerla volver a una condición de animali. dad: Rousseau protesta de esta equivocada interpretación manifestando que él hombre no debè de ningún modo renunciar a su condición humana. Rousseau siente con orgullo y entusiasmo el alto rango de la naturaleza humana y la ensalza y exalta. El hombre es el único ser sobre la tierra que "sabe observar todos los otros seres, medir, calcular, prever sus movimientos, sus efectos, y unir, por así decirlo, el sentimiento de lã existencia común al sentimiento de la existencia individual... Puede observar, conocer los seres y sus relaciones; puede sentir lo que es el orden, la belleza, la virtud; puede contemplar el universo, elevarse hasta la mano que lo gobierna; puede amair el bien, hacerlo". "Si soy asi, ¿̇cómo se me podría comparar con los animales?... Contento con el puesto en que Dios me ha colocado, no veo nada mejor, después de El, que mi propia especie; y si tuviese que escoger mi lugar en el orden de los seres, ¿qué cosa mejor podría elegir que ser hombre?" 4 Añade en otro pasaje del Emilio: "Téngase en cuenta, en primer lugar, que al querer fornar el hombre de la naturaleza, no se trata con esto de hacer de él un salvaje y relegarlo al interior de los bosques. Basta con que, envuelto en el torbellino social, no se deje arrastrar por las pasiones ni por las opiniones de los hombres; basta con que vea con sus ojos y sienta con su corazón; basta con que ninguna autoridad lo gobieme fuera de la de su pro. pia razón.".

O dicho con otras palabras: Rousseau no trata de suprimir la situación social ni el Estado con sus autoridades. : Lo que pretende es hallar los criterios para convertir en justa la sociedad que tantas injusticias ha producido. El hombre, al someterse a la organización política y social justa, que es la

3 Cf. Rodolfo Mondolfo, Rousseau y la conciencia moderna, trad. por V. P. Quintero, Ediciones Imán, Buenos Aires, 1943, pág. 19.

4 Rousseau, Emilio, lib. Iv. 
que responde a la idea del contrato social, según la fórmula que de éste dará en su libro dedicado a tal tema, aunque queda privado de algunas de las ventajas que tendría en un hipotético estado de naturaleza, adquiere ven. tajas mayores: "sus facultades se despliegan y se desarrollan, sus ideas se ensanchan, sus sentimientos se ennoblecen, su alma toda se eleva a tal punto, que si los abusos de esta nueva condición no colocasen por debajo de aquella de la que procede, debería bendecir sin cesar el instante feliz que lo arrancó para siempre de ella y que de un animal limitado y estúpido hizo un ser inteligente y un hombre".

La vuelta a la naturaleza, anhelada y propugnada por Rousseau, bien mirada es un acto del espiritu: es el retorno del hombre a sí mismo, para encontrar de nuevo y escuchar la voz viva que brota de la intimidad de su conciencia: ${ }^{6}$

A pesar de la atracción que sobre Rousseau parecen ejercer algunos aspectos de la vida de los primitivos, de unos primitivos que no son hombres en puro estado de naturaleza, pues entonces se trataría más bien de simples animales, sino que poseen ya las características esenciales de lo humano (comunicabilidad, perfectibilidad, inteligencia racional, etc.), Rousseau no piensa en serio ni por un momento en que se deba intentar volver a aquella etapa inicial de la historia. Por el contrario, quiere decididamente conservar todos los beneficios de la civilización, sólo que depurándola de los maleficios que en ella se han ido acumulando, de sus distorsiones, deformacionès y excre. cencias.

Adviértase, ante todo, que volver atrás es de todo punto imposible; pero aunque fuese hacedero, que no lo es, ello resultaría indeseable. El propósito debe ser otro: debe ser limpiar la sociedad civilizada de las injusticias que en ella se han venido acumulando. Con otras palabras, el remedio que Rousseau apunta para las desdichas de las grandes sociedades civilizadas de su tiempo, consiste en intentar reestructurarlas de acuerdo con lo que la justicia exige; esto es, consiste en proponerse una rcorganización política regida por leyes generales que garanticen la libertad y la paridad ante el Derecho; en suma, consiste en buscar un orden político mejor.

Cierto que el análisis de la vida de los pueblos primitivos o salvajes pone de manifiesto en ésta algunas virtudes, y descubre algunos criterios éticos que abren el alma a la esperanza. Pero no se trata de querer regresar a etapas definitivamente pretéritas, irreversiblemente pasadas. De lo que se trata es de aprovechar el descubrimiento de aquellos rasgos y de aquellos criterios para aplicarlos como pautas reorganizadoras a la sociedad de su tiempo. Se trata de restaurar la voluntad de la naturaleza en la fase de la civilización, es decir, la idea racional de la justicia y del bien común para que de veras

5 Cf. Giorgio Del Vechio, Il Concetto della Natura e il Principio del Diritto, $2^{\text {a }}$ ed., Bologna, 1922. 
imperen real y efectivamente, y de esta guisa cierren el camino a los egóísmos, làs ambiciones, las envidias, los celos y la malicia.

Rousseau tiene, desde luego, conciencia del papel que en esta empresa puede y debe caberles a las virtudes morales, en las cuales reconoce, desde luego, una gran importancia. Pero Rousseau se plantea el problema no en términos de pura moral, en el sentido estricto de esta palabra. Se lo plantea en otros términos: en términos políticos y jurídicos. Por eso recalca ya aquí el criterio de justicia; y sobre éste pondrá el máximo acento en su libro sobre El contrato social.

A pesar de que en su primer "Discurso" Rousseau presenta las ciencias y las artes como causa de la corrupción moral, después, al desarrollar su pensamiento, ofrece sucesivos análisis a través de los cuales és rectificada aquella afirmación contundente. En el fondo, Rousseau no siente una hostilidad con. trá los progresos de las ciencias y las artes, sino contra el hecho de que la cultura no haya conservado la primacía de los valores éticos. La verdadera. causa del mal, el veneno lento y secreto que corrompe las sociedades, es la inmoderación de los apetitos, es la voluntad de poder y de riqueza; es la fuerza y la extensión de los deseos avasalladores que han perdido toda dirección racional. Lo que en fin de cuentas combate Rousseau no es el progréso científico y artístico, sino el hecho de que la falta de una clara visión moral y la carencia de frenos éticos adecuados no hayan impedido que esos progresos incitaran a los hombres a alimentar sus vicios, ni hayan evitado un mal uso de las conquistas hechas por el espíritu humano. En realidad lo que Rousseau combate es la aplicación indebida y el uso antirracional de las posibilidades y de las incitaciones aportadas por las ciencias y por las artes. En suma, ló que combate es lo que él estima como desviaciones de la ciencia y del arte. Impugna sobre todo el torcido aprovechamiento que de ellas hizo la civilización de su época. Así, también en el campo de la filosofia, Rousseau no reniega de lo que él considera verdadero filosofar, sino de aquello que se le antoja como pervertida sofistería. Para Rousseau, el tema esencial de la filosofía debe consistir en enseñar a los hombres cuáles son sus deberes y cuáles son los principios de la virtud.

En el cuadro sombrío que pinta de la vida civilizada, así como en la delicuescencia poética con que se refiere a la supuesta situación del hombre salvaje más próximo a la naturaleza, Rousseau está influido por diferentes. factores.

Claro que, al fin y a la postre, resultará que ese supuesto estado de naturaleza nunca ha existido. La idea de ese estado de naturaleza desempeña en la filosofía social de Rousseau el papel metodológico de una construcción intelectual para averiguar cuál es la esencia de lo humano - buscar lo humano en su estado prístino, auténtico y permanente-; y para fundar sobre esta esencia su doctrina ética, política y juridica. 
Pero aunque sea asi -y esto es, desde luego, lo más importante y lo más decisivo en su filosofía-i, es cierto también que algunas sus páginas sobre el "estado de naturaleza" fueron influidas - no esencialmente, sino más bien de un modo ocasional - por otros factores. Así, verbigracia, de una parte, la imagen idílica de la vida salvaje fue inspirada en alguna medida por la leyenda de la mitología clásica sobre una supuesta edad de oro en tiempos remotos. De otra parte, seguramente algunas de las consideraciones de nostalgia por la vida simple y de protesta contra los moldes de la civilización de su tiempo constituyen un anuncio del espíritu romántico.

Aquella leyenda mitológica aparece recogida incluso en filósofos e historiadores de la Antigüedad clásica. Así, Platón dice, refiriéndose a la etapa primitiva, que "durante muchas generaciones los hombres de aquellos tiem. pos no conocían los pleitos y las desuniones, que aparecen sólo en la sociedad civil... En aquella época eran más simples, más valientes, más temperantes y más justos en todo". ${ }^{6} \mathrm{Y}$ según Tácito: "Puesto que los primeros hombres aún no tenían ninguna pasión funesta, y eran buenos e irreprochables, vivian por eso sin conocer los castigos ni la coerción; las recompensas eran inútiles, pues se adherían al bien por instinto, y, como sus tendencias eran legítimas, no había lugar para reprimirlas por el miedo." 7 Según Tácito, era el espíritu de igualdad lo que mantenía la armonía entre los primeros hombres; el desorden advino con la ambición, es decir, con el deseo de dominación y de desigualdad. $\mathrm{Al}$ perderse el espíritu de igualdad, fue cuando en lugar de la moderación y de la armonía prevalecieron la ambición y la fuer. za y se estableció el poder arbitrario. También Séneca celebra la vida inocente y dichosa de los hombres primitivos: "Nada ha habido más feliz que aquellos hombres. Disfrutaban en común de los bienes de la naturaleza, la cual les servía como madre... Eran inocentes por la ignorancia del mal."

Por otra parte, hay en Rousseau el anuncio de una voluntad romántica que quiere escapar de los moldes preconstituidos, $\dot{e}$ ir en plena franquía a la búsqueda de lo espontáneo, de lo natural, de lo auténtico. Rousseau sabe que la edad de oro no ha existido jamás, y así lo dice categóricamente varias veces. Lo dice en el Discurso sobre los origenes de la desigualdad. Lo dice en la Carta al señor de Beaumont, contestando precisamente a la objeción de que el estado de naturalezá nunca existió: reconoce que, en efecto, no hubo en ningún tiempo tal situación, pero añade que "puede existir por suposición". Ahora bien, aunque no exista, bien vale la pena de tomar ese estado de naturaleza como inspiración ideal. Lo verán como quimera los que tengan el corazón y el gusto echados a perder. . Para convertirlo en realidad, bastaria con una sola cosa, aunque ella es imposible; bastaría con amarlo. ${ }^{8}$ Así,

6 Platón, Las Leyes, $\mathbf{I}, 3$.

7 Tácito, Anales, r, 3, pár, 26.

8 Rousseau, Emilio, Iv. 
pues, Rousseau no cree que haya habido un estado de naturaleza, ni cree siquiera que pueda instaurarse en el futuro, pero le parece que de su.imagen hipotética puede recogerse inspiración para cultivar las mejores virtudes, evadiéndose de la sociedad corrompida del siglo xvmr.

Añádese a los factores mencionados el hecho de que, en el siglo xvir, varios relatos de viajeros y misioneros esparcieron la leyenda de los buenos salvajes, ponderando su inocencia, su simplicidad, su dulzura y su vida feliz. Incluso Montesquieu, haciéndose eco de algunas de esas narraciones, había cantado el elogio de los primitivos del Paraguay. Y Rousseau se entusiasma con los caribes, los que en su opinión se apartan menos de la naturaleza, y con los patagones que habitan en "una isla desierta y deliciosa, dulce y emo. cionante imagen de la antigua hermosura de la naturaleza, y que parecen confinados en el último rincón del mundo, para servir allí de asilo a la ino. cencia y al amor perseguidos". 9

Ese sentimiento romántico, alimentado por aquellos relatos, persistia en Goethe al decir que "uno desearía a menudo haber nacido en una de las islas de los mares del Sur y poseer los caracteres de los salvajes, a fin de disfrutar, aunque fuese por una sola vez, una existencia humana sin mezclas engaño. sas". ${ }^{10}$

En ese entusiasmo por el hombre primitivo y en esa repugnancia por la civilización, actúa sobre Rousseau también su actitud religiosa. Apóstol de la Providencia, Rousseau deduce de la Bondad Divina la bondad de la natu. raleza humana, en estado originario, y culpa de todas las depravaciones de ésta a la obra de las sociedades históricas. "Convencido de la bondad infinita del Ser Supremo, Rousseau no puede admitir que Dios haya creado malo al hombre, ni que lo haya dotado de malas tendencias. Dudar de la bondad natural del hombre sería dudar de la Bondad Divina." 11 . Claro que Rousseau no puede negar la evidencia de los hechos que muestran la maldad de los hombres; pero atribuye ésta a la acción deformadora de las sociedades históricas. Por eso su preocupación ética principal, que va a dar origen a su filosofía social, política y jurídica, es la de hallar una forma de sociedad que no incurra en aquellos defectos.

Rousseau halla la imagen del hombre primitivo no tanto en los relatos aludidos, cuanto más bien en su propio corazón. Describe la naturaleza humana tal y como él la siente dentro de sí mismo. Puesto que no fue subyugado por los prejuicios ni devorado por las pasiones ficticias, sus ojos no están ofuscados para dejar de ver esos rasgos originarios de la naturaleza humana, los cuales han sido olvidados o desconocidos por tanta gente. Claro que

9 Rousseau, Julia o la ntueva Heloisa, rv, 3 . Lebens.

10 Cf. Johann Peter Eckermann, Gespräche mit Goethe in den letzten Jahren seines

11 Cf. Proal, La Psychologie de Jean+Jacques Rousseau, AIcan, Paris, $193^{\circ}$. 
Rousseau no pretendía que él fuese virtuoso. Por el contrario, tenía clara conciencia de sus pasiones, de sus claudicaciones, de sus vicios, de sus fallas. Pero es que Rousseau no confundia la bondad natural con la virtud. Rousseau descubría en el fondo de sí mismo la bondad natural, la cual no implica ningún mérito; $y$, al mismo tiempo, advertía sus fracasos en el esfuerzo para practicar la virtud que él amaba. ${ }^{12}$

París le ofrece las experiencias de los abusos del Ancien Régime. Aquella sociedad le aparece como un conjunto de hombres artificiales, de pasiones ficticias, de instituciones y de prejuicios contrarios a la naturaleza. "A fuerza de vivir con los esclavos, sentí todo el precio de la libertad."

Después de haber criticado acerbamente las deformaciones que las sociedades históricas han producido en el hombre, quiere Rousseau poner remedio a tales calamidades mediante la adopción de las normas naturales, es decir, de las que se fundan en la auténtica esencia de lo humano. Está con. vencido de que los vicios que erróneamente imputan algunos al corazón hu. mano no son efecto de la naturaleza, antes bien, cree que son producidos por una mala civilización que se ha apartado de las normas naturales, por una mala educación, por una literatura y unas artes que corrompen las cos. tumbres, por unas instituciones políticas y unas leyes positivas que contrarian al auténtico Derecho Natural, por la intolerancia de una religión sobrecargada de dogmas irrelevantes para la moral. Para súperar esos estragos y volver por los fueros de lo natural, que para Rousseau equivale a lo genuino y a lo racional, propone la reforma de la educación en el Emilio, la reforma de la literatura en la Carta a d'Alembert, la reforma del Estado y del Derecho en El contrato social, la reforma de la familia en el Emilio y en la Nuevia Helotsa, la reforma de la religión en la Profesión de fe del vicario saboyano.is

Es preciso delimitar bien, con todo rigor, cuál es el sentido en que Rou. sseau tomó la palabra naturaleza. Adviértase que esta palabra fue empleada profusamente en el pensamiento de los siglos xvi y xvin, pero con sentidos diferentes, $y$, a veces, con una especie de significación tornasolada $y$, por tanto, equívoca.

Por una parte, se usa la palabra "naturaleza" como expresiva de los hechos reales concatenados entre sí por leyes de causalidad, articulados entre si de modo forzoso, o, lo que es lo mismo, como expresiva del orden necesario que se da entre los fenómenos. Entendida la naturaleza en esta acepción, todo hecho real es normal, porque todo hecho constituye el efecto de otros hechos que funcionan como sus causas, esto es, como sus condicionantes. $O$, mejor dicho, entendida la naturaleza en este sentido no cabe establecer diferencias entre normalidad y anormalidad, entre salúd y enfermedad, entre lo bueno y lo malo, entre lo justo y lo injusto, entre lo virtuoso y lo vicioso,

12 Rousseau, Quatrième Lettre a Malesherbes.

13 Cf. Proal, ob. cit., pảg. 118. 
porque todo hecho es efecto de unas causas. Un pulmón tuberculoso es tan natural como un pulmón sano, porque el primero no constituye un milagro al margen de la causalidad, sino que es el efecto de unos agentes causativos, como el segundo es el efecto de otra constelación causal. Desde este punto de vista, una conducta inmoral es tan natural como un comportamiento moral, porque cada una de las dos constituye el efecto de diferentes causas igualmente reales en ambos casos. Un reglamento injusto no constituye un hecho que se haya producido inexplicablemente al margen de las leyes de causalidad o en violación de éstas, sino que, por el contrario, es en efecto de unas causas diferentes de aquellas que engendran un reglamento justo, pero tan reales como éstas. Las diferencias entre lo normal y lo anormal, entre lo bueno y lo malo, entre lo útil y lo inútil, entre lo sano y lo enfermo, entre lo justo y lo injusto, nó son ingredientes constitutivos de una realidad, sino que son estimaciones o juicios de valor, son el resultado de comparar una realidad con pautas axiológicas o con finalidades. El análisis científico de la realidad toma en consideración solamente los hechos integrantes de esa realidad, sus antecedentes necesarios (causas) y sus sub-secuentes forzosos (efectos); trata de averiguar exhaustivamente tales antecedentes y subsecuentes y de poner en claro sus inter.relaciones. Por lo tanto, el examen científico de la realidad se mueve en un solo plano, en el plano de los hechos reales; no establece diferencias valorativas; no formula estimaciones; no pronuncia preferencias; no practica discriminaciones apreciativas. Por el contrario, el punto de vista axiológico juzga sobre las realidades en tanto que ellas cumplen o no cumplen, o cumplen en mayor o menor medida, un ideal o propósito fundado en una estimación, inspirado en un valor. Sobre bases axiológicas se distingue entre lo normal y lo anormal. Desde el punto de vista de. la naturaleza, como conjunto de meros hechos y nada más, tan normal es que unos microbios devoren el organismo humano, como lo es que otro organismo humano mejor pertrechado con defensas o antitoxinas venza y destruya los gérmenes patógenos; pues ambos efectos son el resultado natural de diferentes constelaciones de causas. Pero, en cambio, desde el punto de vista humano, lo segundo es considerado como normal, como valioso, mientras que lo primero es reputado como anormal, como antivalioso. Si hubiese una axiología desde el punto de vista del microbio patógeno, el juicio sería in. verso. Por eso. Goethe decía certeramente que incluso lo que se considera lo más antinatural (desde el punto de vista de un sentido diferente del vocablo naturaleza) es también naturaleza. "Auch das Unnatürlichste ist Natur." 14

Cierto que Aristóteles formuló la idea de las "causas finales"; pero cierto también que toda la ciencia moderna, ya desde el siglo xvi con Telesio y con Bacon, ha expulsado del campo científico esta idea, por improcedente y por perturbadora, o en todo caso, por inútil. Claro que expulsar del dominio de

14 Goethe, Die Natur. 
la ciencia la idea de causas finales no implica una proscripción de tal idea en otros campos, por ejemplo, en el de la metafísica. Nada de eso. Mientras que el principio de la finalidad es estéril e incongruente en el plano de la pura ciencia empírica, por el contrario es no sólo admisible, sino necesario, en la filosofía, como lo es también en el área práctica de la vida humana. El "valor" es un tema imprescindible para la filosofía, más aún, es una de las dimensiones cardinales del problema filosófico. Por otra parte, entiendo que debemos percatarnos de que la vida humana, nuestra existencia, consiste ininterrupidamente en una sucesión de estimaciones. Vivir, en el sentido humano de esta palabra, es tener que estar decidiendo real o implícitamente en cada instante lo que vamos a ser en el momento siguiente, para lo cual hay que elegir entre las varias posibilidades que la circunstancia nos depara en cada situación. Ahora bien, todo elegir entre varias posibilidades implica una preferencia por aquella que se escoge. $\mathrm{Y}$ toda preferencia es la expresión de una estimación de un juicio de valor. Hasta ese punto considero que lo esti. mativo es una dimensión radical, esencial, de nuestra vida. Si se quisiera ex. tirpar el punto de vista axiológico, como incesantemente intentó hacerlo el positivismo, toda la cultura perdería su sentido y quedaria flotando en una nebulosa opaca, y no sólo la cultura sino el hecho de la vida humana.

Sucede, empero, que la palabra naturaleza ha sido empleada en otra acepción diferente de la realidad regida por leyes causales, para expresar otra cosa: ora los valores en que se debe inspirar la acción humana, y en los cuales los hombres deben fundar sus propósitos o sus finalidades; ora los prin. cipios trascendentes de la realidad que rigen a ésta.

A este respecto, dice Del Vecchio: 15 "La realidad, ciertamente, por un lado se nos aparece como sujeta al vínculo de las determinaciones causales que liga inseparablemente todos los fenómenos; pero también se nos revela, además, como animada de un poder espontáneo e inagotable, que dirige y gúa sus procesos y la eleva gradualmente, por sucesivos desenvolvimientos, a nuevas formas y a metas más altas. La naturaleza en este sentido ya no es la unidad mecánica de los fenómenos, la ley de reductibilidad de los consiguientes a los antecedentes, la fórmula rígida y ciega que Hegel llamó 'el cadáver del intelecto', sino que es el principio viviente que agita la mole del universo y se manifiesta en la infinita variedad de su desenvolvimiento; es la sustancia que vemos ya inmune de las angustias de la causalidad; es la razón interior que da norma a todas las cosas y señala sus propias tendencias y fines. Tal concepción de la naturaleza, si se la considera correctamente, no contradice, antes bien, integra y completa la consideración causal... La interpretación teleológica del universo es. . no sólo legítima, sino indeclinable."

No puedo tratar aquí, en el presente estudio, este problema filosófico de la interpretación finalista del universo. Aqui se trata solamente de poner en

15 Cf. Del Vecchio, ob. cit. en la nota 5. 
claro las diferentes acepciones en que' la palabra naturaleza ha sido empleada, para interpretar correctamente cuál es el sentido en que Rousseau emplea este vocablo.

Baste con insistir sobre el siguiente punto. "Según el critèrio de los fines, se establece la distinción (inadmisible según el criterio causal) entre lo normal y lo anómalo, entre lo fisiólógico y lo patológico. En esto último, o sea aquello que produce una perturbación en las funciones del organismo, se juzga como menos natural, o contrario a la naturaleza, aunque sea explí. cable causalmente lo mismo que lo primero, esto es, aunque quepa también en el concepto mecánico... de la naturaleza... Teleológicamente considera. da, la naturaleza nó es principio de identidad sino de jerarquía; no es indiferente o adiáfora con respecto al curso del devenir, no se comprueba siempre en todos los fenómenos, sino que nace de ellos en cuanto aspira a determinados tipos y a determinadas coordinaciones. La naturaleza de algo, en este sentido, es el tipo o señal de su perfección; en lo que todo individuo o caso particular debiera de ser para corresponder al propósito de su propia especie. Vivir conforme a la naturaleza... significa en general realizar en sí el propio fin, o sea obedecer a la norma que surge para cada ser de su propia constitución interior, aunque las manifestaciones exteriores, descarriándose, puedan también, en parte, alejarse de-esa norma." 16

Dejemos a un lado los aspectos, las derivaciones y los problemas de la concepción metafísica y teleológica del universo en regiones diferentes del campo de la conducta humana, y limitémonos a aproximarnos mediante unos sumarios esbozos a la zona del comportamiento del hombre. Cuando en Mo. ral y en Derecho se ha hablado de ley natural, lo natural o la naturaleza no se toma en sentido de realidad causal, sino, por el contrario, como norma ideal de justificación necesaria. Ya nada menos que Santo Tomás, a pesar de su aristotelismo, define el sentido del concepto de naturaleza como base de la ley moral natural. A este respecto, distingue entre naturaleza como hecho y naturaleza como razón, lo cual podría reducirse a la diferencia entre causalidad y finalidad, entre hecho y valor. En sentido estricto, Santo Tomás considera que naturaleza debería oponerse a razón: natural sería en el hombre aquello irracional que tiene de común con los animales. Pero añade que se puede hablar de una naturaleza racional humana, en cuanto que el fin del hombre demanda que el hombre en sus actos se dirija por la razón; y tam. bién en cuanto a los principios prácticos racionales se hallan en el hombre de un modo habitual. Santo Tomás admitía, pues, que hay normas racionales objetivas respecto de la conducta humana; reconocía, por otra parte, la realidad empírica del hombre; y, por fin, entendía que se da una intervención real de aquellos principios racionales por medio de la capacidad innata del hombre de provocar la presencia habitual de esos principios en su mente. La

16 Giorgio Del Vecchio, ob. cit. en la nota 5 . 
norma racional no agota su papel en su objetividad normativa; sino que además constituye, en una peculiar manifestación psíquica de sí misma (la sindéresis), un principio regulativo inherente al ser, al cual va dirigida. De este modo, Santo Tomás establece primero la distinción entre norma y realidad; pero de otra parte tiende un puente de unión entre estos dos mundos. La ley natural es norma racional objetiva, y es, al propio tiempo, un principio regulativo inmanente del hombre, en cuanto habita consustancialmente en él mismo, gracias a la sindéresis. ${ }^{17}$

Ahora bien, sucede que el concepto de naturaleza como base del llamado Derecho Natural sufrió algunas confusiones y se lastró con equívocos en los desenvolvimientos de la Escuela Jusnaturalista clásica del siglo xvir. Ya uno de los más ilustres representantes de esta escuela, Tomasio, advertia cuán difícil es la cuestión sobre cuál sea la índole de la naturaleza (difficilis quaes. tio de naturae).

Varios representantes de la Escuela Clásica del Derecho Natural desplazaron el problema sobre la idea de naturaleza como base de la Axiología ju: rídica hacia el concepto de un "estado de naturaleza". Se pensaba que la naturaleza como criterio normativo se la hallaría en el estado prístino, originario, del hombre, es decir, en la realidad del hombre en situación pura, antes o aparte de las deformaciones y excrecencias que la historia ha ido produciendo en el ser humano. Así, al término natural se le atribuyó el significado de primordial, y se entendia la naturaleza como la génesis inicial de lo humano. Asi habla la tendencia a considerar natural o conforme a la naturaleza la condición primitiva del hombre; y se estimaba como natural el Derecho que se suponía que hubiera debido regir primero entre los hombres en su etapa primera, es decir, cuando brillaba pura y sin degeneraciones su naturaleza auténtica, no velada por la obra de la historia. Se creía que lo deseable es. taba ya ahí como un fruto espontáneo de la realidad; se creía que el hombre era bueno de suyo por naturaleza.

Este modo de pensar no fue exclusivo de la Escuela Clásica del Derecho Natural, sino que existía también en otros campos. Así, Juan Bautista Vico, por otra parte fundador de las ciencias de la cultura y de la teoría de la historia, escribia que la naturaleza de las cosas no es más que el nacimiento de las mismas en ciertos tiempos y de ciertos modos; y siempre que estos tiempos y modos son tales, de ellos nacen tales cosas y no otras cosas. ${ }^{18}$ Ahora bien, en la doctrina de Vico, el concepto de naturaleza aparece claramente en un sentido genético. En cambio, en varios de los iusnaturalistas de la Escuela clásica la idea de naturaleza se da cargada de equívocos, es decir,

17 Cf. IV Sent. d. 33, q. 1, a. Véase: Luis Recaséns Siches, La filosofía del derecho de Francisco Sudrez, con un estudio previo sobre sus antecedentes en la pairistica y en la. escolústica, $z^{\text {a }}$ ed. Editorial Jus, México, 1949, págs. 65-68.

18 Vico (Giambattista), Ciencia nueva, trad. de José Carner, El Colegio de México, México, 1941, libro r; Degli Elementi, ş xıv, r y xv. 
con tornasoles de sentido: por una parte, pretende ser equivalente a norma fundada en la esencia del ser humano; mas, por otra parte, se la concibe como una etapa primitiva, real o supuesta, en oposición con lo sobreve. nido después, por obra de la sociedad, a lo largo de la historia. Así, por ejemplo, en Pufendorf.

Aunque los iusnaturalistas clásicos, así como también otros pensadores, verbigracia Hobbes, hablan a veces del "estado de naturaleza" como de una situación real en los albores de la humanidad, sucede, sin embargo, resulta en fin de cuentas, que esos autores en el fondo están manejando tal idea más bien como una hipótesis de trabajo, con el propósito de descubrir cuál sea la auténtica esencia del hombre por contraste con todo lo demás accidental que en él se ha producido. Llegan esos pensadores a comprender, o por lo menos a entrever, que tal estado de naturaleza nunca ha existido de hecho, y que constituye tan sólo una construcción de la mente para lograr el concepto de lo que es esencial al hombre, con el propósito de que esa esencia suministre las pautas normativas necesariamente válidas.

Rousseau depurará hasta su máximo extremo algunos de esos modos del pensamiento de la Escuela Clásica del Derecho Natural y de Hobbes, pero seguirá empleando muchas veces, por tradición, aquellas expresiones equívocas. Por eso algunos lectores poco avisados, o poco atentos, han caído en la ligereza de creer que Rousseau suponía que efectivamente había existido un estado de naturaleza, a pesar de que Rousseau dice categóricamente que tal estado de naturaleza no existió jamás.

También muchos otros pensadores en el siglo xvin, contemporáneos de Rousseau, predicaban una reforma moral, religiosa, política y jurídica, basada en un retorno a la naturaleza. Sin embargo, algunos emplean equívocamente la palabra naturaleza, en una acepción predominante de realidad empírica y, por lo tanto, con un sentido y con algún alcance muy diferentes de lo que este concepto significa en Rousseau, La Mettrie, en su Discurso sobre la felicidad ( 1748 ), habia propugnado la aplicación de las leyes naturales a la moral, y había bosquejado una ética fundada sobre la tendencia a la felicidad, cuya realización requiere el ejercicio de las virtudes, especialmente del amor al prójimo y del servicio a la humanidad. También Saint Lambert había pedido la aplicación de las leyes naturales a la conducta humana. Holbach escribió El sistema de la naturaleza y el sistema social o principios naturales de la moral y de la politica $\left(\mathbf{1}_{7} 6_{7}\right)$. Diderot compuso en $17^{6} 9$ sus Pensa. mientos sobre la interpretación de la Naturaleza, obra en la cual tiende a una comunión del hombre con el mundo natural. Morelly, en su Código de la Naturaleza (1755), había esbozado una organización colectivista supuestamente fundada en leyes naturales. En cambio, Voltaire sostenía una con. cepción finalista de la naturaleza como la obra sabia de Dios, regida por un orden finalista. 
Ahora bien, Rousseau protestó siempre contra cualquier intento de em. parejar a la suya propia cualquiera de aquellas filosofías. Para Rousseau, la naturaleza en moral y en religión es una especie de íntima Revelación Divina de las normas auténticas, válidas en sí mismas, las cuales se manifiestan en la conciencia. "La conciencia es la voz del alma; las pasiones son la voz del cuerpo...; la conciencia no engaña jamás. . ; quien la sigue obedece a la naturaleza." Su reforma política, Rousseau quiere fundarla estrictamente sobre el Derecho Natural, entendido como Derecho Racional, es decir, como razón aplicada a la fundamentación, la organización y el funcionamiento del Estado, por consiguiente, como criterio para la justificación y el desarrollo del Derecho.

\section{El conocimiento de la esencia de lo humano}

¿Y cómo podría llegar el hombre a verse tal como lo ha formado la naturaleza, a través de todos los cambios que la sucesión de los tiempos y de las cosas ha debido producir en su constitución original, y a distinguir lo que tiene de su propio fondo frente a lo que las circunstancias y sus progresos han cambiado o añadido a su estado primitivo? Semejante a la estatua de Glaucos, que el tiempo, el mar y las tempestades habían desfigurado de tal modo que menos se parecía a un dios que a uria bestia salvaje, el alma humana, modificada en el seno de la sociedad, por mil casusas que renacen sin cesar, por la adquisición de una multitud de conocimientos y de errores, por las transformaciones ocurridas en la constitución de los cuerpos y por el continuo choque de las pasiones, ha cambiado, por así decirlo, de aparien. cia, hasta el punto de que apenas puede ser reconocida. Y así resulta que, en lugar de hallar un ser obrando siempre conforme a principios ciertos e invariables, en lugar de la celestial y majestuosa simplicidad de que su Autor la habia dotado, lo que encontramos es el disforme contraste de la pasión que cree razonar y del entendimiento en delirio.

Esta es una de las ideas fundamentales de toda la filosofía de Rousseau. Cuando contemplamos el espectáculo de lo humano nos hallamos ante una riquísima variedad de diferencias según los diversos lugares, según los tiempos sucesivos, según las situaciones históricas. Este espectáculo no proporciona a primera vista una imagen del hombre, antes bien, por el contrario, una multiplicidad de imágenes muy diversas. Ahora bien, lo que Rousseau desea hallar en la auténtica naturaleza de lo humano en sí, aparte de sus accidentes, es lo permanente a través de todos los cambios. Este pensamiento requiere dos comentarios. Primero, el análisis de por qué Rousseau busca una naturaleza esencial y permanente de lo humano. Segundo, la explicación de por qué supone que esa naturaleza esencial de lo humano se identifica con la idea de lo humano en estado originario, en su situación prístina. 
Rousseau busca la naturaleza del hombre como algo universal y perma. nente, como su consistencia fundamental, porque - al igual que la mayor parte del pensamiento de la Edad Moderna - ha heredado de la filosofía griega esa idea de la naturaleza de las cosas como una textura persistente, idéntica a sf misma en todos los casos. Esa idea ha resultado fecunda en el estudio de la naturaleza física. Pero, en cambio, fracasó en el estudio del hombre. Había fracasado ya en la época de Rousseau y éste tiene conciencia de tal falla. Comentando esa quiebra de la razón naturalista, dice José Ortega y Gasset: "Cuando la razón naturalistả se ocupa del hombre..., busca poner al descubierto su naturaleza. Repara en que el hombre tiene cuerpo - que es una cosa- y se apresura a extender a él la física, y, como este cuerpo es además un organismo, lo entrega a la biología. Noța asimismo que en el hombre, como en el animal, funciona cierto mecanismo incorporal o confusamente adscrito al cuerpo, el mecanismo psíquico, que es también una cosa, y encarga de su estudio a la psicología, que es ciencia natural. Pero es el caso que llevamos así trescientos años y que todos los estudios naturalistas sobre el cuerpo y el alma del hombre no han servido para aclararnos nada de lo que sentimos como estrictamente humano... Lo humano se escapa a la razón físico-matemática como el agua por una canastilla." 19

Rousseau barruntaba ya este fracaso, mejor dicho, se daba cuenta de él, aunque tal vez no con plena claridad. Lo cierto es que cuando Rousseau emprende una indagación sobre la naturaleza del hombre en el Discurso sobre la desigualdad va a esbozar una antropología filosófica en un plano diferente del de las ciencias de la naturaleza física. Pero aunque sea así, conservará -y esto es lo grave- una idea de naturaleza como algo idéntico a sí mismo y permanente, como una magnitud constante, ya dada desde que una cosa es originada. Lo cual no es un modo de pensar exclusivo de Rousseau, sino que es una dirección que dominó la mayor parte de los estudios de lo humano desenvueltos sobre una base diferente de la naturaleza física. En efecto, cuando las llamadas ciencias del espíritu, en guerra contra el naturalismo fisicista, tratáron de aprehender lo humano, aplicaron al hombre el concepto de cosa, de res de la ontologia tradicional, en la cual "el término res va siempre conjugado con el de natura, bien como sinónimo, bien en el sentido de que la natura es la verdadera res, el principio de la res. Como es sabido, el concepto de naturaleza es de pura sangre griega: recibe una primera estabilización en Aristételes, que, modificada por los estoicos, entra en el Renacimiento y por aquel gran boquete inunda la época moderna... Ahora bien, poner como condición a lo real, para que sea admitido como tal, que consista en algo idéntico, fue la inmensa arbitrariedad de Parménides y, en general, de todo el

10 Cf. Ortega y Gasset, La historia como sistema. Madrid, 1941 (en Obras completas, tomo vi, Madrid, 1947, pág. 24). 
pensamiento griego ortodoxo". ${ }^{20}$ Cuando se trata de concebir lo humano desde un punto de vista diferente del de la naturaleza física, biológica y psicológica, desde el punto de vista que vagamente solía llamarse espiritual, se sigue pensando la denominada naturaleza espiritual del hombre como cosa, como res. Todo lo sutil, lo etérea, que se quiera, pero con una consistencia estática, fija, permanente, substante, que es ya y desde luego, todo lo que es y va a ser.

Rousseau no busca en el hombre una naturaleza naturalista, valga la expresión, física o biológica. Es cierto que tampoco reduce al hombre a espiritu o a intelecto, sino que se forja una imagen compleja de lo humano, subrayando los sentimientos. Es cierto, además, que Rousseau halla la historicidad (bajo la versión de la progresividad como dimensión esencial del hombre, en tanto que individuo, y en tanto que especie humana, con lo cual átisba nada menos que la razón vital y la razón histórica. Pero es cierto tam. bién que, avasallado por la tradición del ser como lo idéntico a sí mismo y lo substante, como res, se lanza a la búsqueda de una natura humana, fija, cons. tante, permanente. Ahora bien, hay que reconocer y advertir - dicho sea de modo especial en y para honor de Rousseau-, que éste, cual expondré más adelante en el presente artículo, se da cuenta de que muchas conductas y muchos aspectos del hombre que eran cargados en la cuenta de la naturaleza humana, son tan sólo comportamientos aprendidos, modos cúlturales, por lo tanto, son algo histórico.

A Rousseau le interesa averiguar cuál sea la naturaleza del hombre, con el fin de poner en claro las normas necesarias válidas para su conducta, en suma, para fundar la Etica, tanto la Moral como el Derecho. O, expresado con otras palabras, lo que Rousseau busca es el ideal de la conducta humana. Ahora bien, cree - como he explicado ya - que lo que el hombre debe ser es lo que corresponde a su auténtica esencia, a su ser genuino, y que ese ser genuino y esencial es lo que el hombre sería en estado químicamente puro, tal y como salió de las manos de Dios, antes de que las sociedades históricas hubiesen producido en él excrecencias, deformaciones, degeneraciones que han venido a ocultar su ser verdadero. $Y$, en algunas ocasiones, se deja llevar eventualmente por la tendencia de suponer que ese hombre verdadero es el que existió, o pudo existir — pues él sabe que de hecho no existió-, en los orígenes de la humanidad. En esa tendencia, bastante generalizada en el siglo xviI - y aun ya antes, en el xviI-, influían a la vez el mito pagano de una edad de oro y el dogma cristiano del estado de inocencia de la primera pareja en el Paraíso antes de la comisión del pecado original. Digo que Rous. seau sabe que tal estado originario de naturaleza, en el que el hombre se hallase en situación químicamente pura, no existió jamás. Lo dice explícitamente, sin dejar sombra de duda, cuando escribe: "pues no es ligera empresa

20 Cf. Ortega y Gasset, ob. cit., en la nota precedente, pág. 27. 
distinguir lo que hay de originario y lo que hay de artificial en la naturaleza actual del hombre, y conocer bien su estado, que no existe ya, que acaso no ha existido, que probablemente no existió nunca, pero del cual es necesario, sin embargo, tener justas nociones para juzgar acertadamente nuestro estado presente". Lo reconoce en un párrafo posterior cuando critica el hecho de que la mayor parte de los filósofos no han dudado de que hubiera existido el estado natural, "cuando es evidente, por la lectura de los libros sagrados, que el primer hombre, habiendo recibido directamente de Dios reglas y entendimiento, no se hallaba por consiguiente en ese estado, y que, concediéndose a las escrituras de Moisés la fe que les debe todo filósofo cristiano, debe negarse que, aun antes del diluvio, se hayan encontrado nunca los hombres en el puro estado natural".

El concepto de estado de naturaleza representa, para Rousseau, el medio de averiguar cuáles sean los principios ciertos e invariables, las normas uni. versal y necesariamente válidas para la conducta, normas que entiende se derivan de la esencia auténtica de lo humano tal y como ésta fue creada por Dios. "Haría falta más filosofía de lo que se piensa a quien emprendiera la tarea de determinar exactamente las precauciones necesarias para hacer sólidas observaciones sobre este asunto; y no me parecería indigna de los Aristóteles y Plinios de nuestro siglo una buena solución del problema si. guiente: ${ }_{i} Q u e ́$ experiencias serian necesarias para llegar a conocer al hombre natural, y cuáles son los medios de hacer estas experiencias en el seno de la sociedad?

"Estas investigaciones tan difíciles de hacer y en las cuales tan poco se ha pensado hasta ahora son, sin embargo, los únicos medios que nos quedan para resolver una multitud de dificultades que nos impiden el conocimiento de los fundamentos reales de la sociedad humana." 21

Ésta es una de las manifestaciones en que Rousseau hace patente de modo inequívoco que lo que él llama "estado de naturaleza" no constituye una realidad en la historia o en la prehistoria del hombre, sino que es un concepto construido por la mente con el fin de expresar la esencia auténtica de lo humano. Cierto que en numerosos pasajes habla del estado de naturaleza como si éste hubiese existido efectivamente en los origenes de la humanidad. Al expresarse de ese modo se deja llevar por la fuerza de esta imagen y, sobre todo, por la inercia del lenguaje usado por muchos autores del siglo xvin, no pocos de los cuales, sin embargo, empleaban tales expresiones también en sentido metafórico. Pero hay momentos, como en éste, en el que Rousseau siente la necesidad de aclarar las cosas con toda precisión, para que el lector no llegue a creer que el estado de naturaleza existió de hecho.

21 Cf. Rousseau, Discurso sobre los origenes y los fundamentos de la desigualdad entre los hombres. 
El estado de naturaleza es una hipótesis de trabajo, un caso limite construido por la mente, para poner en claro la genuina esencia del hombre.

El carácter de hipótesis de trabajo o de caso límite que el estado de naturaleza tiene en la obra de Rousseau se confirma decisivamente por el hecho de que se le ocurra hablar, al menos en principio, de las experiencias para llegar a conocer al hombre natural en el seno de la sociedad. Que Rousseau considere que ni siquiera los más grandes filósofos tendrían capacidad suficiente para dirigir tales experiencias, no desvirtúa el argumento que aca. bo de indicar: el argumento de que en principio sería posible, aunque resultase dificilísimo, sacar a flote la auténtica esencia de lo humano dentro de la civilización histórica. Por otra parte, el hecho de que Rousseau diga que ni siquiera los más poderosos soberanos serían capaces de poner en práctica tales experiencias, demuestra que Rousseau no navega en absoluto por el reino de la Utopía, sino que tiene los pies firmemente clavados en la reali. dad, y que conoce todas las limitaciones de ésta. A Rousseau le importa des. cubrir los principios ideales de la naturaleza normativa, en primer lugar, por un interés teórico de esclarecer la esencia de lo humano, y por uno práctico de descubrir los principios del Derecho Natural. También, porque cree que el conocimiento de esos principios suministrará la fuente de correcta inspira. ción para una mejor organización política y para un mejor Derecho. Pero no sueña con que esos principios de Derecho Natural puedan llegar a ser plenamente realizados en ningún pueblo.

Mas si este conocimiento del verdadero Derecho Natural, cuando se lo. gre, no traerá como secuela necesaria la posibilidad de realizarlos de hecho plenariamente, en cambio ofrecerá, sin duda, los medios para tratar de mejor manera muchos problemas sociales. Rousseau experimenta la necesidad de un mejor conocimiento no sólo de los principios normativos ideales, sino también de los fundamentos reales de la sociedad humana.

Rousseau lamenta aquí la tremenda confusión de ideas sobre el llamado Derecho Natural, precisamente por el sentido equívoco en que se ha empleado la idea de naturaleza como fundamento del Derecho que debe ser.

Precisamente lo que se propone es aclarar la idea de la naturaleza humana como fundamento normativo del ideal de Derecho.

Rousseau está de acuerdo con los autores modernos que piensan la natu. raleza, no como hecho real, sino como norma ideal prescrita al hombre. Ésta es la dirección que Rousseau va a acentuar todavia más, y que Kant llevará a su extrema pureza.

\section{Los ingredientes sociales de la personalidad humana individual}

Dice Rousseau que “... es fácil ver que, entre las diferencias que dis. tinguen a los hombres, pasan por naturales muchas que son únicamente obra 
de la costumbre y de los diversos géneros dè vida que llevan los hombres en la sociedad. Así, un temperamento.fuerte o delicado, la fuerza o la debilidad que de éste dependen, proceden con frecuencia más de la manera ruda o afeminada con que uno ha sido criado, que de la constitución primitiva del cuerpo. Lo mismo sucede con las fuerzas del espíritu, y no solamente la educación establece diferencias entre los espíritus cultivados y los que no lo están, sino que aumenta la que existe entre los primeros en proporción con la cultura, pues si un gigante y un enano van por el mismo camino, cada paso que adelanten dará una nueva ventaja al gigante. Ahora bien: si. se compara la prodigiosa variedad de educación y de géneros de vida que reina en los dife. rentes órdenes del estado civil con la simplicidad y la uniformidad de la vida animal o salvaje, en la cual todos se nutren con los mismos alimentos, viven del mismo modo-y hacen exactamente las mismas cosas, se comprenderá entonces cómo la diferencia de hombre a hombre debe ser menor en el estado de naturaleza que en el de.sociedad, y cómo la desigualdad natural debe aumentar en la especie humana por la desigualdad de educación".22

Con su pentrante visión, Rousseau se da cuenta de que la personalidad concreta de cada individuo-está constituida en gran medida por una especial combinación de los efectos que la sociedad ha ido dejando en él. Entiendo que tal personalidad concreta se halla integrada y determinada por múltiples y variados factores de diversas clases (biológicos "constitucionales" y biológicos "adquiridos", psíquicos "constitucionales" y psiquicos "adquiridos", por el sentido y conciencia del yo profundo, único e insustituible, y por una serie de ingredientes de carácter social). Dentro de la clase de ingredientes o factores sociales de la personalidad los hay de muy variados tipos, por ejemplo: ideas trasmitidas por el prójimo a nuestro alrededor; ideas aprendidas en los libros; modelados o configuráciones que son el efecto de la influencia ejercida sobre nuestros modos de pensar, de sentir, de reaccionar y de actuar por otros seres humanos, bien por determinadas personas con quienes hemos estado en extensa e íntima relación, como por ejemplo, nuestros padres, her. manos, amigos de infancia, bien por los miembros de los grupos a que pertenecemos :(v. gr.: vecindad, comunidad local, estirpe étnica, escuela, comunidad nacional, círculo cultural, clase social, profesión, etc.); modos de comportamiento que son, en alguna medida, la reacción frente a conductas de otras gentes con quienes estamos o hemos estado en trato; maneras de comportamiento que son el resultado de las lecciones sacadas de experiencias de anteriores relaciones sociales; aptitudes y prácticas configuradas por la presión de la opinión pública dominante, de las creencias colectivas prepon. derantes, de las costumbres en vigor; actitudes y conductas que representan una imitación - consciente o inconsciente - de otras personas; hábitos ad. quiridos en el cumplimiento de modos sociales de vida; hábitos formadós en $22 O b$, cit. en la nota precedente. 
el ejercicio de una profesión; la huella efectiva dejada en el subconsciente por experiencias infantiles; o la huella más o menos consciente impresa por experiencias en la edad adulta; las ambiciones estimuladas por el ejemplo de otros individuos; la euforia y optimismo producidos por triunfos sociales; el apocamiento, la desconfianza o la inseguridad que previos fracasos crean en el ánimo; preferencias, aficiones, entusiasmos o fobias que se le meten a uno dentro por contagio del medio social ambiente en que se vive; etc.

Aquí tenemos una magnífica aportación a la Antropología filosófica, al apuntar la observación sobre la enorme variedad de lo humano. Este punto ha sido desenvuelto a fondo y con precisión de análisis en el pensamiento posterior del siglo xIx, pero sobre todo, en el de nuestra época. Frente a la uniformidad animal en cada una de las especies zoológicas hallamos una ilimitada diversidad en el reino de la vida humana. ${ }^{23}$

Todo ello fue barruntado certeramente por Rousseau, quien en este punto, al igual que en muchos otros, se anticipó a su época.

Luis Recaséns Siches

23 Véase sobre estos puntos: Luis Recaséns Siches, Tratado general de sociología, 2a ed. Editorial Porrúa, México, 1958, págs. 117-127, 137-199. 